\title{
2 Generación del mapa de cobertura y uso del suelo de la provincia del Azuay
}

Tenesaca Pacheco, Carlos'; Quindi Pomavilla, Toa²; Delgado Orellana, Gabriela; Toledo López, Edgar4; Delgado Inga, Omar

Instituto de Estudios de Régimen Seccional del Ecuador IERSE, Universidad del Azuay Av. 24 de mayo 7-77

Biólogo con mención en Ecología y Gestión por la Universidad del Azuay, maestrante de Gestión Ambiental en la Universidad del Azuay, investigador en el IERSE de la Universidad del Azuay en el área de sensores remotos de teledetección.

carlostenesaca.ct@gmail.com

Ingeniera Ambiental por la Universidad de Cuenca, maestrante de Gestión Ambiental en la Universidad del Azuay.

\section{Carlos} Tenesaca Pacheco $^{1}$

toa_q@yahoo.es

Ingeniera Ambiental por la Universidad Politécnica Salesiana sede Cuenca, maestrante de Gestión Ambiental en la Universidad del Azuay.

Toa

Quindi Pomavilla²

gabbycha_99@hotmail.com

Ingeniero Agrónomo por la Universidad de Cuenca, Diplomado superior en gestión ambiental con mención en protección del medio ambiente físico otorgado por la Universidad del Azuay, investigador en el IERSE de la Gabriela
Delgado
Orellana $^{3}$ Universidad del Azuay en el área de ordenamiento territorial.

\section{Edgar Toledo López $^{4}$}

toledoedgar62@yahoo.com 
Ingeniero en Minas por la Universidad del Azuay, Master Universitario en Tecnologías de la Información Geográfica por la Universidad Alcalá de Henares, Especialista en sistemas de información geográfica aplicados a la gestión territorial y ambiental por la Universidad del Azuay. Docente e Investigador en el IERSE de la Universidad del Azuay.

odelgado@uazuay.edu.ec

\section{Resumen}

La Universidad del Azuay, a través del Instituto de Estudios de Régimen Seccional del Ecuador (IERSE), suscribió un convenio de cooperación interinstitucional con el Gobierno Provincial del Azuay para la generación del "Mapa de Cobertura Vegetal y Uso de Suelo de la provincia del Azuay, a escala 1:5.000", con base en las ortofotografías del año 2010, generadas por el proyecto SIGTIERRAS del Ministerio de Agricultura, Ganadería, Acuacultura y Pesca (MAGAP). La generación de la cartografía temática se realizó en tres etapas: a) recopilación de información de ortofotografías suministra- das por la SENPLADES; b) definición de la leyenda de trabajo realizada en base a la información del mapa de cobertura y uso del suelo, generado por el MAGAP-MAE 2015; y c) digitalización de elementos geográficos y tratamiento digital de imágenes, la cual se realizó mediante el uso de sistemas de información geográfica (SIG) obteniendo como resultado 33 capas de información de elementos geográficos naturales y antrópicos.

\section{Palabras clave:}

Cobertura vegetal, uso del suelo, ortofotografía, provincia del Azuay.

\begin{abstract}
The University of Azuay, through the Institute of Studies of Sectional Regime of Ecuador (IERSE), signed an agreement of interinstitutional cooperation with the Provincial Government of Azuay for the generation of the "Map of Vegetation Cover and Land Use of the province of Azuay, scale 1:5,000" Based on the 2010 orthophotographs generated by the SIGTIERRAS project of the Ministry of Agriculture, Livestock, Aquaculture and Fisheries (MAGAP). The generation of thematic cartography was carried out in three stages: A) compilation of orthopho-
\end{abstract}

to information provided by SENPLADES; B) definition of the work legend based on the information of the map of coverage and land use generated by MAGAP-MAE 2015; and c) digitalization of geographic elements and digital image processing which was done through the use of geographic information systems (GIS) Resulting in 33 layers of information from natural and man-made geographic elements.

\section{Keywords:}

Vegetal cover, land use, orthophotography, province of Azuay. 


\section{Introducción}

El Ecuador dispone de información cartográfica para la planificación territorial y el manejo de los recursos naturales, entre la que está el "Mapa de Cobertura y Uso de la Tierra del Territorio Nacional a escala 1:100.000", que emplea como insumo la información de sensores remotos 20132014, disponible al público desde junio de 2015 por parte del Ministerio de Agricultura, Ganadería, Acuacultura y Pesca (MAGAP), el Ministerio de Ambiente de Ecuador (MAE) y la Secretaría Nacional de Planificación y Desarrollo (SENPLADES). La información generada tiene la finalidad de propender al mejoramiento del nivel de productividad del sector agropecuario, monitorear los impactos ambientales del hábitat vegetal y contar con información consolidada e integrada para las dos primeras instituciones.

La Universidad del Azuay, a través del Instituto de Estudios de Régimen Seccional, ha generado el "Mapa de Cobertura Vegetal y Uso de Suelo, a escala 1:5.000 de la provincia del Azuay", con base en la ortofotografía del año 2010 del proyecto SIGTIERRAS, el cual se ha confrontado y validado utilizando la información del mapa de cobertura y uso del suelo generado por el MAGAP-MAE 2015, que está a una escala 1:25.000.

\section{2. Área de estudio}

La provincia del Azuay, situada al sur del país, tiene una superficie de 8.326,6 $\mathrm{km}^{2}$, según los límites referenciales del Instituto Nacional de Estadísticas y Censos (INEC, 2012), con una población de 712127 habitantes. Es la quinta provincia más poblada del país según el último censo nacional (INEC, 2010); está constituida por 15 cantones que incluyen a 27 parroquias urbanas y 60 rurales.

En la provincia existen dos zonas diferenciadas, al este los Andes occidentales y orientales y al oeste la región costa, estas condiciones del relieve han determinado la presencia de siete pisos bioclimáticos que contienen 23 ecosistemas, entre estos el herbazal de páramo, bosque siempreverde montano y las zonas intervenidas.

La provincia cartográficamente está cubierta por 1.725 ortofotos a escala 1:5.000, de las cuales se disponen 1.425 ortofotos con su respectivo modelo digital de terreno, que corresponde el $82 \%$ de la superficie del territorio.

\section{Metodología}

El estudio se desarrolló en tres etapas:

1. Recopilación de la información de ortofotografía a escala 1:5.000

2. Definición de la leyenda de cobertura vegetal y uso del suelo

3. Tratamiento digital de imágenes y digitalización de elementos geográficos

\subsection{Recopilación de la información de ortofotografía a escala 1:5.000}

El proyecto SIGTIERRAS del MAGAP realizó la toma de fotografía aérea a nivel nacional, a escala 1:20.000 con un tamaño de pixel del suelo establecido (Ground Sample Distance) de $30 \mathrm{~cm}$ para la sierra, $40 \mathrm{~cm}$ para la costa y $50 \mathrm{~cm}$ para el oriente; lo que generó la ortofotografía a escala 1:5.000. (MAGAP, 2015) 


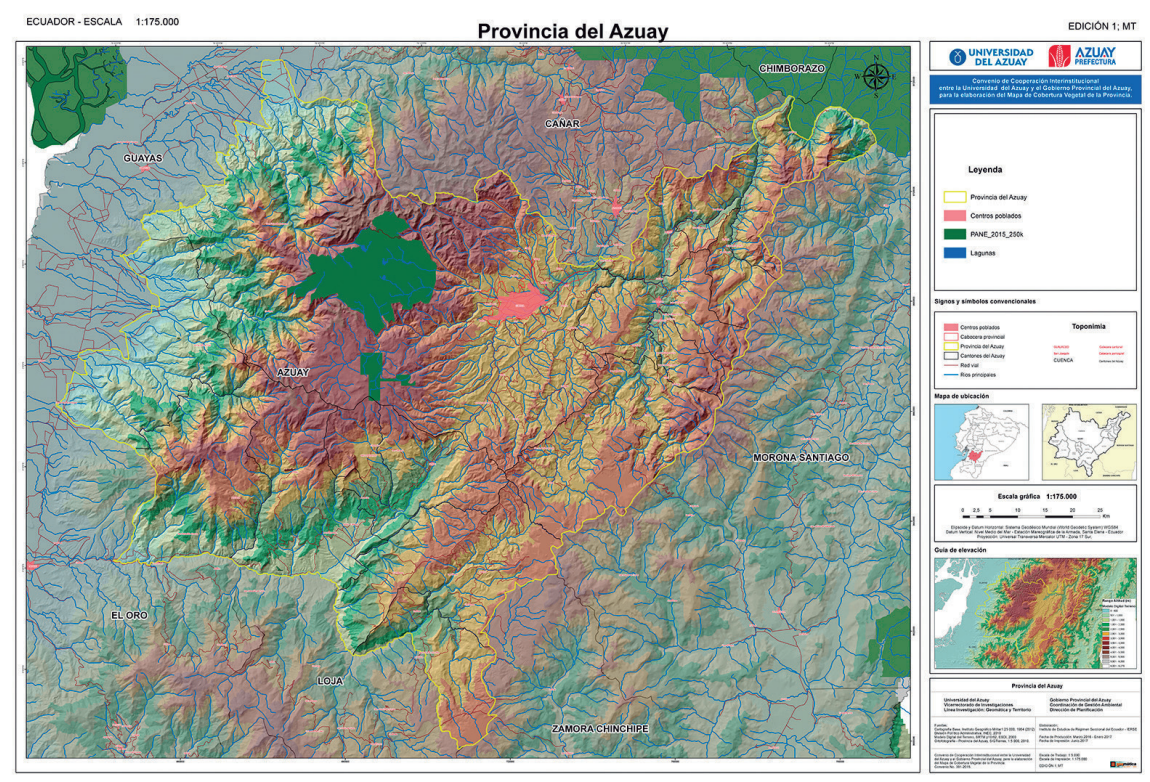

Figura 1. Mapa de ubicación de la provincia del Azuay

Las ortofotos de SIGTIERRAS fueron entregadas por la SENPLADES a los GAD's para la actualización de los planes de desarrollo y ordenamiento territorial. Cada ortofoto está conformada por 7745 columnas y 7702 filas (2323.5 m x 2310,6 m), con un perímetro de $9.268,2 \mathrm{~m}$ y una superficie de 536,9 ha, almacenadas en 227,6 MB en formato raster. Las ortofotos están conformadas por cuatro bandas: B1 (rojo), B2 (verde), B3 (azul), B4 (infrarrojo cercano).

\subsection{Definición de la leyenda de} cobertura vegetal y uso del suelo

La leyenda fue definida con base en la información del mapa de cobertura vegetal y uso del suelo generado por el MAGAP-MAE, en el año 2015 a escala 1:25 000. 
Tabla 1. Leyenda de cobertura vegetal y uso del suelo

\begin{tabular}{|c|c|c|c|}
\hline CóD. & $\begin{array}{l}\text { TIPOS DE USO Y } \\
\text { NIVEL I }\end{array}$ & $\begin{array}{l}\text { COBERTURA DEL SUELO DE } \\
\text { NIVEL II }\end{array}$ & $\begin{array}{l}\text { LA PROVINCIA DEL AZUAY } \\
\text { NIVEL III }\end{array}$ \\
\hline \multirow{6}{*}{1} & \multirow{6}{*}{ BOSQUE } & Bosque nativo & Bosque nativo \\
\hline & & \multirow{5}{*}{ Plantación forestal } & Plantación forestal de eucalipto \\
\hline & & & Plantación forestal de pino \\
\hline & & & Plantación forestal de eucalipto / pino \\
\hline & & & Asociación forestal \\
\hline & & & Plantación talada \\
\hline \multirow{4}{*}{2} & \multirow{4}{*}{$\begin{array}{l}\text { VEGETACIÓN } \\
\text { ARBUSTIVA Y } \\
\text { HERBÁCEA }\end{array}$} & Vegetación arbustiva (chaparro) & Vegetación arbustiva (chaparro) \\
\hline & & Vegetación herbácea & Vegetación herbácea \\
\hline & & \multirow{2}{*}{ Páramo } & Pajonal \\
\hline & & & Almohadilla o humedal \\
\hline \multirow{4}{*}{3} & \multirow{4}{*}{$\begin{array}{l}\text { TIERRA } \\
\text { AGROPECUARIA }\end{array}$} & \multirow{2}{*}{ Cultivos } & Suelo cultivado \\
\hline & & & Suelo arado \\
\hline & & \multirow{2}{*}{ Pastizales } & Pasto con manejo \\
\hline & & & Pasto degradado \\
\hline \multirow{8}{*}{4} & \multirow{8}{*}{ AGUA } & \multirow{3}{*}{ Cuerpos de agua } & Lago o laguna \\
\hline & & & Reservorio \\
\hline & & & Embalse \\
\hline & & \multirow{3}{*}{ Cursos de agua } & Ríos \\
\hline & & & Quebradas \\
\hline & & & Canal de riego \\
\hline & & \multirow{2}{*}{ Vegetación lacustre } & Totora \\
\hline & & & Lechuguín \\
\hline \multirow{3}{*}{5} & \multirow{3}{*}{ ERIAL } & Afloramiento rocoso & Afloramiento rocoso \\
\hline & & \multirow{2}{*}{ Áreas sin cobertura vegetal } & Suelos erosionados \\
\hline & & & Suelos descubiertos \\
\hline \multirow{4}{*}{6} & \multirow{4}{*}{$\begin{array}{l}\text { ZONAS } \\
\text { ANTRÓPICAS }\end{array}$} & Área poblada & Área poblada \\
\hline & & \multirow{2}{*}{ Vías } & Vías \\
\hline & & & Senderos \\
\hline & & Infraestructura & Estructuras diversas \\
\hline 7 & $\begin{array}{l}\text { OTRAS } \\
\text { COBERTURAS }\end{array}$ & Área quemada & Área quemada \\
\hline \multirow{4}{*}{8} & \multirow{4}{*}{ SIN INFORMACIÓN } & Cubierta humo & Cubierta humo \\
\hline & & Nubes & Nubes \\
\hline & & Sombra & Sombra \\
\hline & & Sin Información & Sin Información \\
\hline
\end{tabular}

Fuente: MAGAP-MAE, 2015 


\subsection{Digitalización de} elementos geográficos y tratamiento digital de imágenes

El mapa de cobertura vegetal y uso del suelo se generó a partir de:

- Digitalización de elementos geográficos

- Tratamiento digital de imágenes

\subsubsection{Descripción del proceso de digitalización de elementos geográficos}

En la digitalización se obtuvo información de elementos geográficos naturales y antrópicos empleando un sistema de información geográfica (SIG).
El procedimiento consistió en digitalizar los elementos geográficos presentes en las ortofotos mediante la creación de archivos shape de tipo polígono y línea dependiendo del elemento, a una escala mínima en pantalla de 1:800 para generar cartografía a escala 1:5.000.

Los elementos digitalizados comprenden cinco categorías generales:

- Agua: cuerpos de agua, cursos de agua y ríos colectores

- Tierras agropecuarias: suelo arado y suelo cultivado

- Zonas antrópicas: estructuras diversas, vías y senderos

- Otras coberturas: áreas quemadas

- Sin información: nubes y sombras.

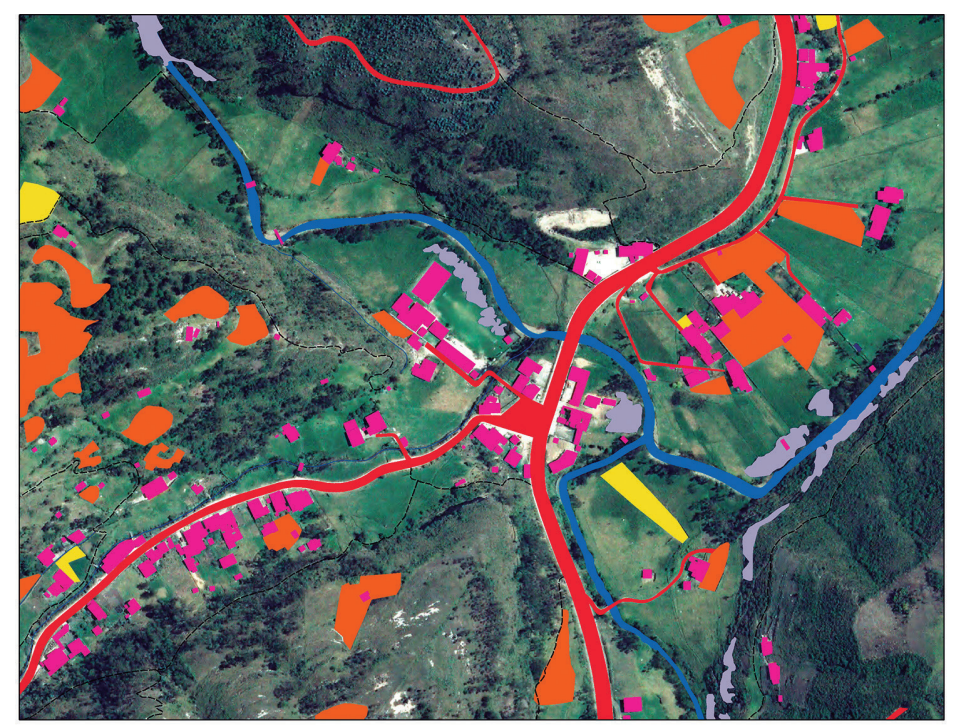

Figura 2. Elementos digitalizados - parroquia Tarqui, cantón Cuenca. Fuente: Autores 


\section{Categoría agua: cuerpos de agua, cursos de agua y ríos colectores}

Areas saturadas y recorridos cubiertos de agua, estáticas o en movimiento, de origen natural o artificial, que reposan sobre la superficie terrestre por todo o una parte del año. Áreas de vegetación propias de los sistemas lacustres o que se hallan en las masas de agua.

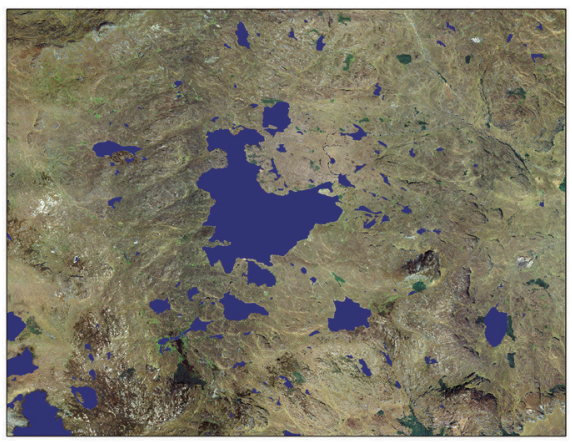

Figura 3. Cuerpos de agua - parroquia Sayausí, cantón Cuenca (Parque Nacional (ajas). Fuente: Autores

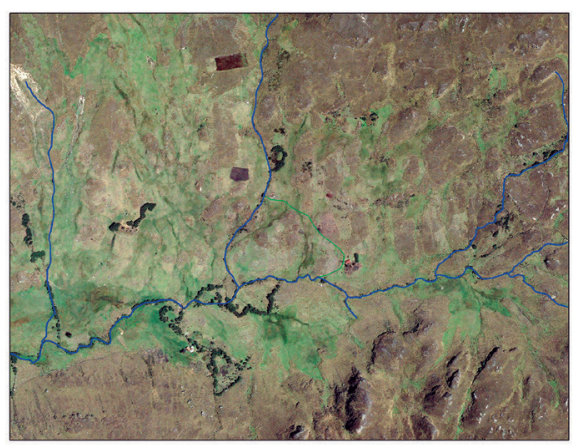

Figura 4. Cursos de agua - parroquia Zhaglli, cantón Santa Isabel. Fuente: Autores

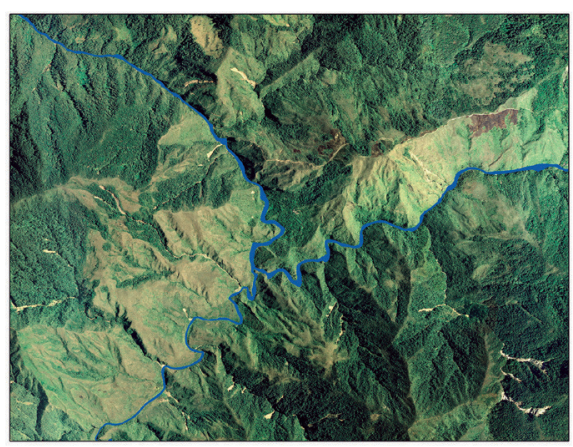

Figura 5. Ríos - cantón Sígsig (Río Santa Bárbara). Fuente: Autores

\section{Cuerpos de agua}

Digitalizados como polígono, contienen lagos o lagunas naturales alimentadas por quebradas; y artificiales que incluyen reservorios o lagunas construidas con fines de riego. Además, los cuerpos de agua contienen la nomenclatura según la base de datos del Instituto Geográfico Militar (IGM) a escala 1:50 000

\section{Cursos de agua}

Se digitalizó en tipo línea las quebradas, canales de riego y ríos pequeños con un ancho promedio de un metro, que pueden observarse a una escala 1:800 utilizando como referencia la información disponible en la base de datos del IGM escala 1:50.000.

\section{Río colector}

Se digitalizó en tipo polígono los ríos colectores, de los cuales se puede calcular el área que ocupan así como su perímetro. Los ríos colectores fueron identificados y nombrados según la base de datos del IGM a escala 1:50.000. 


\section{Categoría tierra agropecuaria: suelo arado y suelo cultivado}

Áreas de cultivo agrícola, que se encuentran en producción o en preparación del suelo. Áreas cubiertas de pastizales con prácticas de mejoramiento o pastos cultivados en forma tradicional.

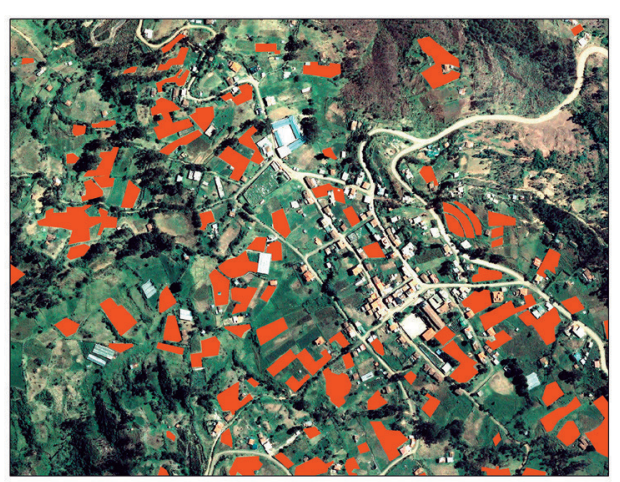

Figura 6. Suelo arado - parroquia Jadán, cantón Gualaceo. Fuente: Autores

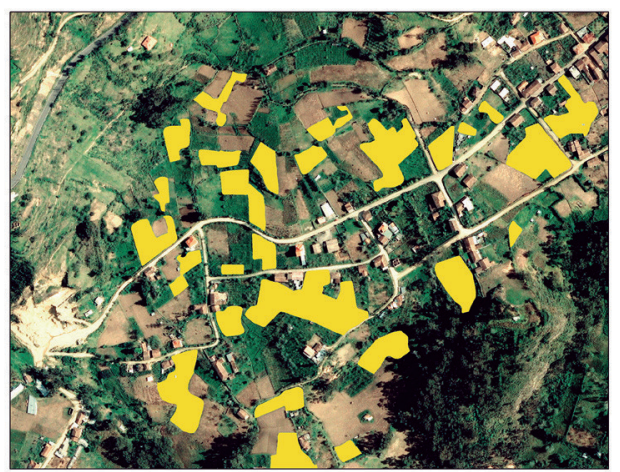

Figura 7. Suelo cultivado - parroquia San Bartolomé, cantón Sígsig. Fuente: Autores

\section{Suelo arado}

Se digitalizó como polígono las porciones de terreno donde se planea realizar una siembra o están recientemente sembrados o cosechados, considerando los surcos característicos realizados por el arado animal o mecánico.

\section{Suelo cultivado}

La digitalización se realizó con polígonos en zonas o porciones de terreno en donde es evidente la presencia de suelo cultivado. 


\section{Categoría zonas antrópicas: estructuras diversas, vías y senderos}

Asentamientos humanos y la infraestructura que la complementa.

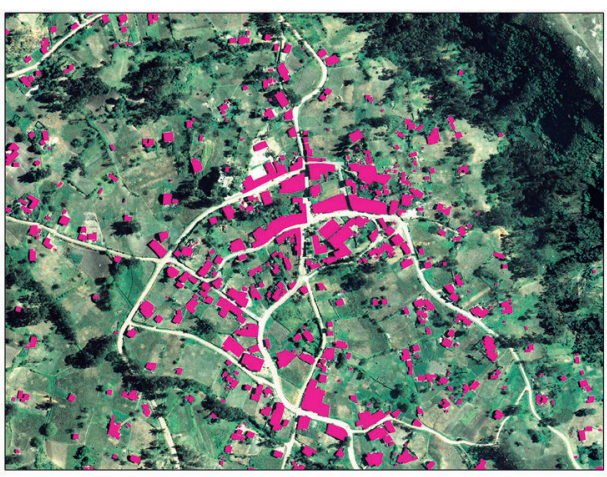

Figura 8. Construcciones - parroquia Llacao, cantón Cuenca. Fuente: Autores

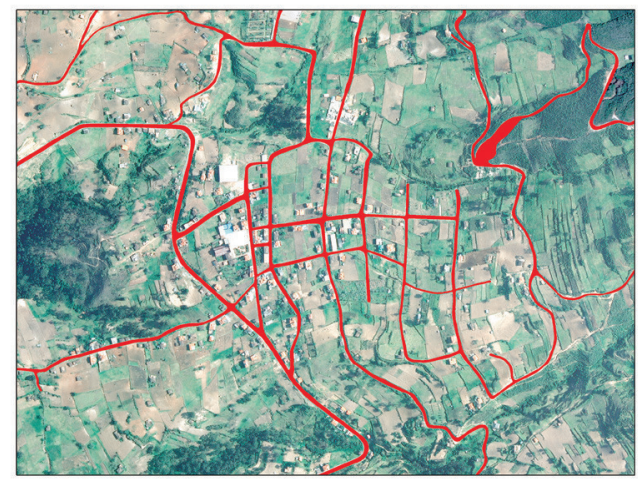

Figura 9. Vías - parroquia San Martín de Puzhio, cantón Chordeleg. Fuente: Autores

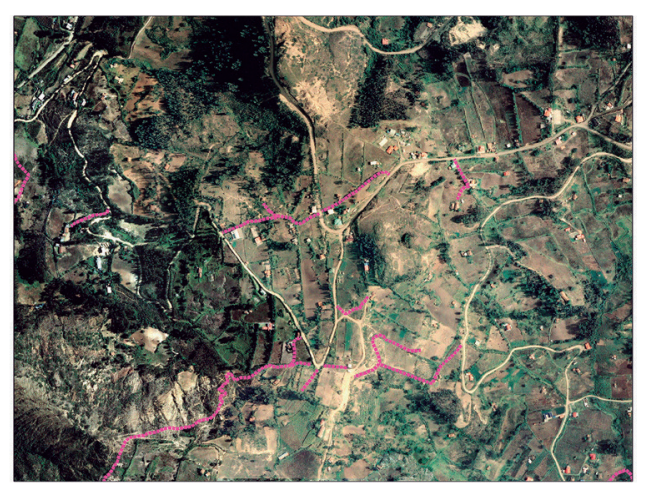

Figura 10. Senderos - parroquia San Cristóbal, cantón Paute. Fuente: Autores

\section{Construcciones}

Se digitalizó como polígono, empleando herramientas que permiten dibujar de manera ortogonal e incluyen: casas, invernaderos, puentes, escuelas, parques, iglesias, tanques de agua, plantas de tratamiento de agua, entre otros equipamientos mayores.

\section{Vías}

Digitalizadas como polígono las vías con un ancho promedio mayor a 2 metros, es decir, vías para circulación vehicular.

\section{Senderos}

Se digitalizó en tipo línea aquellos caminos que se encontraban dentro de un centro poblado o se dirigían a una casa en específico. 


\section{Categoría otras coberturas: áreas quemadas}

Áreas en las que la información (al momento de su captura) es casual o eventual.

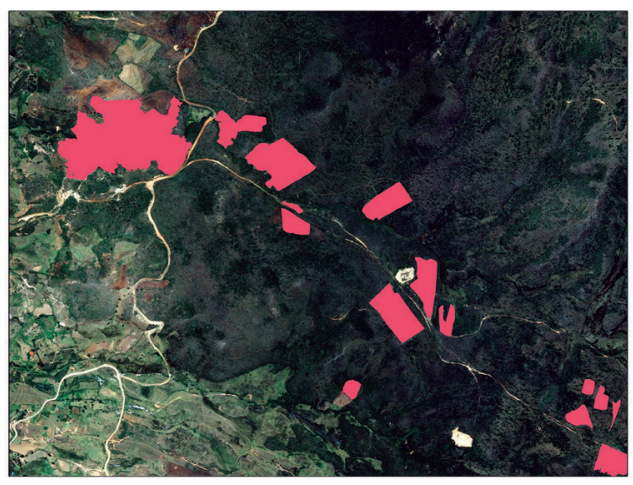

\section{Área quemada}

Se digitalizó como polígono aquellas zonas donde se evidenciaba una coloración característica de incendios o quemas controladas.

Figura11. Área quemada - parroquia San

Felipe de Oña, cantón Oña. Fuente: Autores

\section{Categoría sin información: nubes y sombras.}

Áreas que no han sido mapeadas por falta de información.

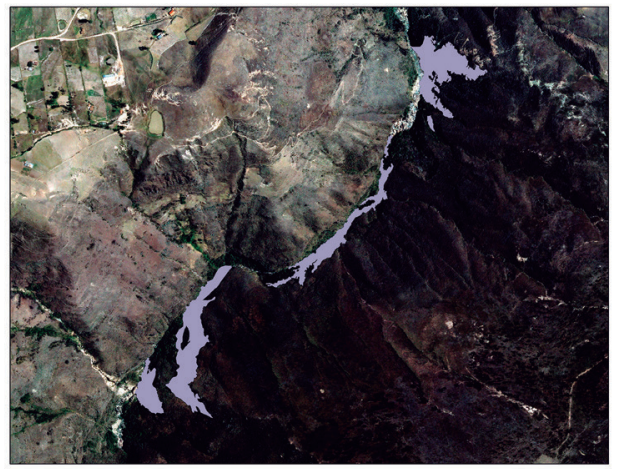

\section{Sombras}

Se digitalizó como polígono las zonas con carencia de iluminación, lo que impide la identificación del tipo de cobertura.

Figura 12. Sombras - parroquia Las Nieves, cantón Nabón. Fuente: Autores 


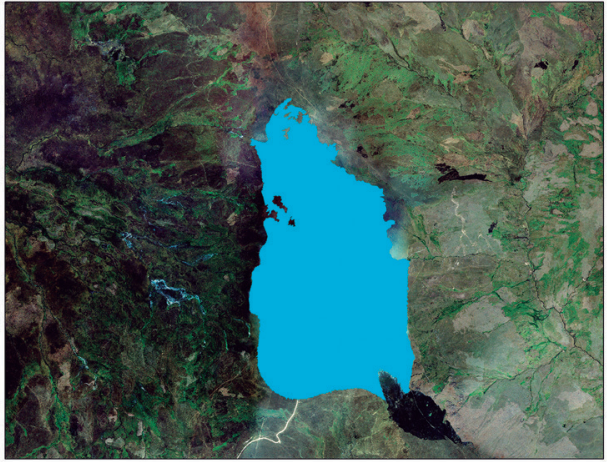

Figura 13. Nubes - parroquia Baños, cantón Cuenca. Fuente: Autores

\subsubsection{Depuración de los} elementos digitalizados

Se ejecutó un proceso de mejora, que consistió en realizar un suavizado de polígonos y líneas con lo que se obtuvo un afinado de los ángulos cerrados en contornos de los polígonos para mejorar la calidad estética y cartográfica. Método utilizado: aproximación polinomial con núcleo exponencial (PAEK), como se muestra en la figura 14.

\subsubsection{Descripción del proceso de tratamiento digital de imágenes (TDI)}

\section{Nubes}

Se digitalizó a manera de polígono las nubes con áreas relevantes, que ocasionaban dificultades en la identificación de cobertura vegetal.

\subsubsection{Tratamiento digital de imágenes (TDI) - Clasificación basada en objetos}

Para el tratamiento digital de imágenes partimos de la definición del sistema de coordenadas geográficas de las ortofotografías, posteriormente se continúa con la identificación de las coberturas y uso del suelo en cada ortofoto. Las coberturas identificadas en la provincia del Azuay corresponden a bosque nativo, plantación forestal de eucalipto, plantación forestal de pino, plantación forestal de eucalipto / pino, asociación forestal, plantación talada,
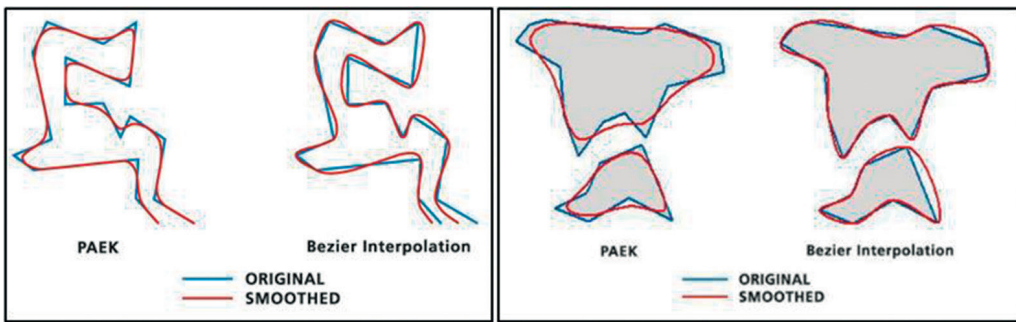

Figura 14. Método de suavizado de polígonos y líneas. Fuente: Environmental Systems Research Institute, Inc. 
vegetación arbustiva (chaparro), vegetación herbácea, pajonal, almohadilla o humedal, pasto con manejo, pasto degradado, suelos descubiertos entre otras coberturas. (tabla 1)

Cada ortofotografía de la provincia del Azuay fue sometida a TDI mediante clasificación basada en objetos, aplicando algoritmos sobre las propiedades en cada ortofotografía, lo que se sintetiza en los siguientes procesos:

1. Identificación de bandas espectrales en ortofotografía (Red, Green, Blue, NIR)

2. Segmentación basada en objetos

3. Identificación de las coberturas presentes en ortofotografía

4. Aplicación de algoritmos en función de las propiedades de los objetos (índices de vegetación, textura, brillo, tamaño, forma)

5. Obtención de la información clasificada

\subsubsection{Depuración y edición de la información}

Como primer criterio para la información obtenida se basó en el área mínima cartografiable, la cual garantiza operatividad cartográfica y adecuada lectura de un mapa (Salitchev, 1979), y considerando que los productos cartográficos a obtener son a escala 1: 5.000, el área mínima cartografiable es de $400 \mathrm{~m}^{2}$.
Los resultados del tratamiento digital de imágenes se encuentran en formato raster y mediante sistemas de información geográfica se procede a mejorar la información aplicando filtros para depurar los elementos ya clasificados.

En la depuración de la información se realizaron los siguientes procesos:

1. Cargar el archivo raster resultante del TDI-clasificación basada en objetos

2. Aplicar herramientas para la delimitación de bordes y homogenización de la información, que servirá para depurar los límites entre coberturas

3. Clasificar la información por tipo de cobertura

4. Extraer el valor del área mínima cartografiable y rellenar los vacios resultantes de la extracción con valores de su vecino más cercano.

5. Obtener datos y revisión detallada de las coberturas identificadas

\subsubsection{Corrección topológica}

Para garantizar la calidad de las relaciones espaciales y facilitar la compilación de datos se analizó la topología, lo que permitió encontrar errores asociados con la geometría de las capas del archivo shape, para ello fue necesario crear una geodatabase, y dentro de esta crear la topología a la cual se añadieron dos reglas: las entidades

Tabla 2. Área mínima cartografiable según la escala gráfica

\begin{tabular}{|c|c|c|c|c|c|c|}
\hline \multirow[t]{2}{*}{ Escala } & \multicolumn{2}{|c|}{$1 \mathrm{~cm}$ igual a } & \multicolumn{2}{|c|}{$1 \mathrm{~mm}$ igual a } & \multicolumn{2}{|c|}{ Área mínima cartografiable ( 4 x $4 \mathrm{~mm}$ ) } \\
\hline & m & km & m & km & $\mathrm{m} 2$ & km2 \\
\hline $1: 2.000$ & 20 & 0.02 & 2 & 0.002 & 64 & 0.000064 \\
\hline $1: 5.000$ & 50 & 0.05 & 5 & 0.005 & 400 & 0.0004 \\
\hline 1: 10.000 & 100 & 0.1 & 10 & 0.01 & 1.600 & 0.0016 \\
\hline 1: 500.000 & 5.000 & 5 & 500 & 0.5 & 4.000 .000 & 4 \\
\hline
\end{tabular}

Fuente: Área minima cartografiable para diferentes escalas (Salitchev, 1979) 
no deben superponerse, es decir, pueden compartir ejes o vértices; pero no superponerse los polígonos; y que no existan huecos, es decir, esta regla precisa que no haya vacíos dentro de un polígono simple o entre polígonos adyacentes. Todos los polígonos deben formar una superficie continua.

\subsubsection{Revisión y validación}

Para garantizar un producto confiable se recurrió a dos sistemas de revisión y validación de la información obtenida. Primero se confrontaron y corrigieron las coberturas, utilizando la información del mapa de cobertura y uso del suelo generado por el MAGAP-MAE 2015. Segundo, se realizaron visitas al territorio en las que mediante muestras de diferentes coberturas y usos permitieron comprobar y validar la información procesada.

\subsubsection{Integración de la información de elementos geográficos digitalizados con el tratamiento digital de imágenes}

Obtenida la información de la digitalización de elementos geográficos y del tra- tamiento digital de imágenes se procedió a unir dicha información, considerando dos criterios:

- Eliminación de entidades sobrepuestas entre el mapa de cobertura vegetal y uso del suelo y los elementos de digitalización.

- Corrección de errores topológicos

\section{Resultados}

Como resultado del estudio se obtuvieron los siguientes productos:

- Geodatabase de elementos digitalizados naturales y antrópicos contenidos en 11 capas de información: cuerpos de agua, cursos de agua, ríos colectores, suelo arado, suelo cultivado, estructuras diversas, vías, senderos, nubes, sombras y área quemada.

- Geodatabase de mapa de cobertura vegetal y uso del suelo a escala 1:5.000 contenida en 33 capas de información indicadas en la tabla 3.

El registro de la generación de la información cartográfica cuenta con estructura de metadatos.

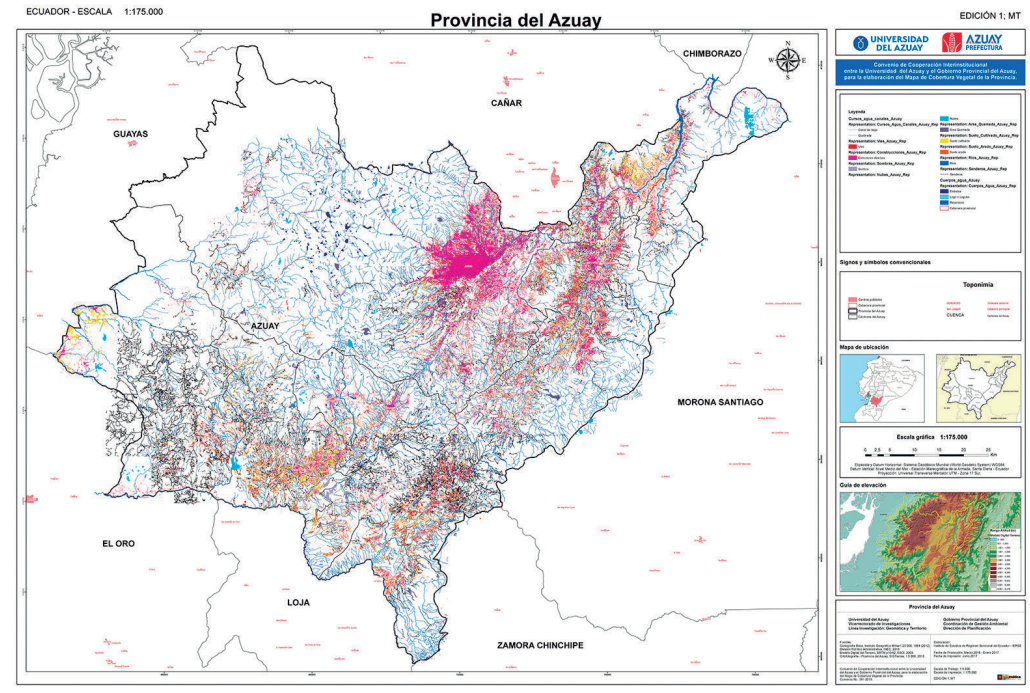

Figura 15. Elementos digitalizados naturales y antrópicos de la provincia del Azuay 

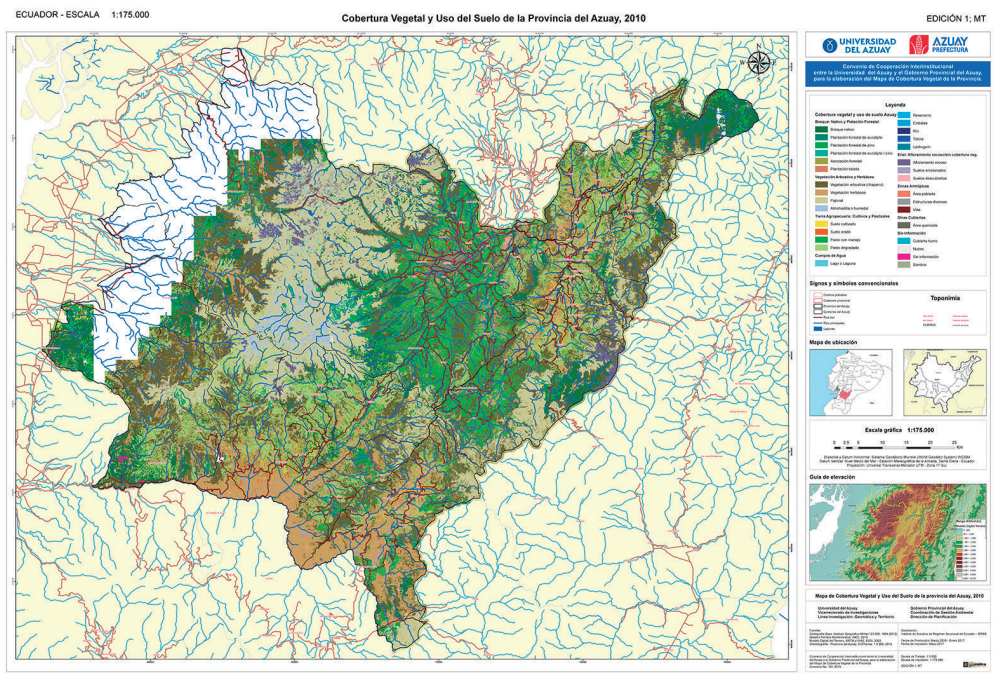

Figura 16. Mapa de cobertura y uso del suelo de la provincia del Azuay

Tabla 3. Cobertura vegetal de la provincia del Azuay

\begin{tabular}{|l|l|r|l|r|r|}
\hline Cód. & NIVEL III & Área (ha) & Cód. & NIVEL III & Área (ha) \\
\hline 1 & Afloramiento rocoso & 15085,6 & 18 & Plantación forestal de pino & 8714,1 \\
\hline 2 & Almohadilla o humedal & 11914,2 & 19 & Plantación talada & 23,8 \\
\hline 3 & Área poblada & 2970,1 & 20 & Plantas de tratamiento de agua & 46,2 \\
\hline 4 & Área quemada & 1640,7 & 21 & Represas & 26,8 \\
\hline 5 & Área verde & 414,1 & 22 & Reservorio & 111,2 \\
\hline 6 & Asociación forestal & 533,6 & 23 & Ríos & 881,7 \\
\hline 7 & Bosque nativo & 63721,2 & 24 & Sin información & 9388,3 \\
\hline 8 & Cubierta humo & 30,4 & 25 & Sombra & 637,1 \\
\hline 9 & Embalses & 820,4 & 26 & Suelo arado & 1906,1 \\
\hline 10 & Lago o laguna & 1836,2 & 27 & Suelo cultivado & 829,2 \\
\hline 11 & Lechuguín & 149,3 & 28 & Suelos descubiertos & 12932,3 \\
\hline 12 & Nubes & 1511,3 & 29 & Suelos erosionados & 4142,9 \\
\hline 13 & Pajonal & 147901,1 & 30 & Totora & 27,7 \\
\hline 14 & Pasto con manejo & 82686,7 & 31 & Vegetación arbustiva (chaparro) & 202120,1 \\
\hline 15 & Pasto degradado & 114568,1 & 32 & Vegetación herbácea & 80343,2 \\
\hline 16 & Plantación forestal de & 12523,9 & 33 & Vías & 1634,6 \\
\hline 17 & eucalipto & Plantación forestal de & 612,4 & & \\
\hline & eucalipto / pino & & & \\
\hline
\end{tabular}




\section{Conclusiones}

Las tecnologías de la información geográfica TIG son herramientas necesarias para el tratamiento de imágenes provenientes de sensores remotos, porque contribuyen a generar información cartográfica de diferentes temáticas diferenciadas en elementos geográficos naturales y antrópicos.

Contar con información detallada a escala 1:5.000 de la provincia, sobre cobertura vegetal y uso del suelo: agrícola, conservación, regeneración, suelo urbano, entre otros, constituyen insumos de base para la planificación y gestión del territorio en los diferentes niveles de gobierno: provincial, cantonal y parroquial.

Las instituciones de educación superior, a través de convenios con los GAD, pueden fortalecer la planificación territorial mediante el asesoramiento, capacitación técnica y transferencia tecnológica.

\section{Agradecimiento}

Expresamos nuestro agradecimiento al equipo de fiscalización de la Dirección de Planificación del Gobierno Provincial del Azuay por la confianza depositada en el IERSE para la generación del mapa de cobertura vegetal y uso del suelo de la provincia del Azuay, a escala 1: 5.000.

Nuestro reconocimiento al equipo técnico del IERSE, que laboró en los procesos de digitalización y tratamiento digital de imágenes, conformado por profesores, profesionales contratados, estudiantes del programa de pasantía de geomática y territorio año 2016-2017.

\section{Bibliografía}

Chuvieco, E., (2010). Teledetección Ambiental. Editorial Ariel Ciencia, Barcelona, España.

Galeas, J., (2012). Proyecto Mapa Vegetal del Ecuador Continental. Ministerio del Ambiente del Ecuador. Quito, Ecuador.

Instituto Geográfico Militar IGM. (2012). Cartografía base de la provincia del Azuay escala 1:50.000.

Instituto Nacional de Estadísticas y Censo INEC. (2010). Censos de Población y Vivienda.

Instituto Nacional de Estadísticas y Censo INEC. (2012). Cartografía digital de división política administrativa a nivel provincial, cantonal y parroquial.

Ministerio de Agricultura, Ganadería, Acuacultura y Pesca MAGAP. (2015). Proyecto SIG Tierras.

Salitchev, K. A. (1979). Cartografía: La Habana: Cuba. Ministerio de Educación, Pueblo y Educación, 1

Secretaría Nacional de Planificación y Desarrollo SENPLADES. (2013). Plan nacional de desarrollo 2013-2017. 